\title{
LEGIBILITY
}

A

A major purpose of the Technical Information Center is to provide the broadest dissemination possible of information contained in DOE's Research and Development Reports to business, industry, the academic community, and federal, state and local governments.

Although a small portion of this report is not reproducible, it is being made available to expedite the availability of information on the research discussed herein. 

MID-INFRARED ADJLSTABIE, COHERENT I.IGHT EXPERIMENT (MIRACLE) FACILITY'

AUTHOR(S): A. H. Lumpkin, r-15

D. W. Feldman, R. W. Warren, W. F. Stcin, J. M. Watson, AT-7

J. E. Sollid, B. F. Newnam, C.I.S-6

J. C. Goldstein, X-1

W. J. Johnson, AT-5

iUBMITTED TO: The 10th International Free Flectron Laser Conference, August 29 -

September 2, 1988, Jerusalem, Israel 
PROPOSED EXTENDED TUNING RANGE FOR THE LOS ALAMOS MID-INFRARED ADJUSTABLE, COHERENT LIGHT EXPERIMENT (MIRACLE) FACILITY'

A. H. L.umpkin, D. W. Feldman, J. E. Sollid,

R. W. Warren, W'. E. Stein, B. E. Newnam, J. C. Goldstein, W. J. Johnson, and J. M. Watson

Los Alamos National Laboratory

Los Alamos, NM 87545

\begin{abstract}
The Los Alamos Free-Electron Laser (FEL) Facility has been in operation as an oscillator in the $10 \mu \mathrm{m}$ wavelength regime since 1983. Operations from 10 to $45 \mu \mathrm{m}$ have been recently demonstrated which would provide a new applications capability: A Mid-Infraced Adjustable Soherent Light Experiment (MIRACLE) Facility. We propose to extend this tunability from 3 to $160 \mu \mathrm{m}$ by upgrading the injector, accelerator, and resonator cavity. Potential applications in material science (high-temperature superconductors) and biophysics (DNA spectroscony) for this wavelength regime are briefly addressed.
\end{abstract}

\title{
I. INTROI)U("TION
}

Broadbarid wavelength tunability is one of the most attractive features of a frecelectron laser (liti.). Our efforts at l.os Alachos have been concentraled on high power operations at $10 \mu \mathrm{m}$ (1). although tunability had beer demonstrated from 9 (1) $35 \mu \mathrm{m}$ previously [2]. A projected extension of this range from $3 \mu \mathrm{m}$ (1) $160 \mu \mathrm{m}$ would provide a needed complement to the existing IIIL. applications research facilities in the U.S. that operate in the visible, (Stanford SCA), the few micron (Stanford Mark III), and the sub millimecter regimes (University of (alifornia at Santa Barbara).

Recently, we demonstrated the Lunability of our Mi:l Infiared Adjustable, robetent l.ight I xperiment (MIR ACl.I) Facility and extended our operations $1145 \mu \mathrm{m}$. W'e used copper mirrors with a 1 mm diame:er outcoupling hole in !ne of the mirrors. The peresent

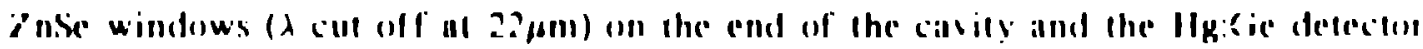

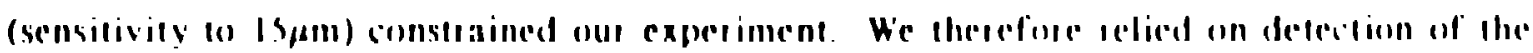

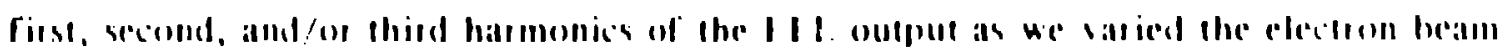


energy. Extraction of energy from the electron beam was monitored on our electron spectrometer as well as by the optical measurements.

We propose to change the cavity window to allow longer wavelength transmission (diamond is onc candidate), obtain a zinc or copper-doped Germanium detector for extended wavelength coverage, and modify our IR spectrometer for operations at the longer wavelengths. We would then tune to longer wavelengths and ultimately establish an optical path up to the user laboratory.

Potential applica:ions in material science and medical physics for this wavelength regime will be addressed.

\section{EXPERIMIENTAL CONSIDERATIONS}

\section{A. Experimental Procedures and Results}

The Los Alamos FEL is an RF-linac-driven oscillator that has been operated nominally at about $10.6 \mu \mathrm{m}$ since 1983 ll]. The e-beam pulse structure (and hence the

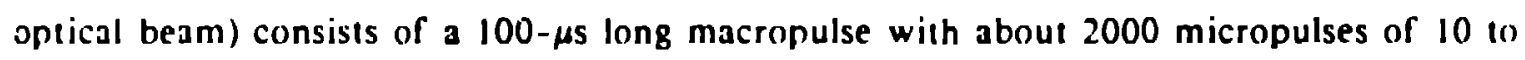
20-ns duration separated by $46 \mathrm{~ns}$. The nominal operating parameters are given in Table $\mathrm{I}$. The present experimental beam line is shown in Fig. I. The injector, two accelerator sections, the $60^{\circ}$ achromatic bend, the wiggler, and resonator cavity are indicated.

Recent improvements in operational capability are cescribed elsewhere in this Conference [3,4]. In particular, the optical bandwidth of $0.3 \%$ was at the transform limit: wavelength chirping was achieved by a prescribed e-beam energy ilew within a macropulse: sideband suppression was demonstrated by hoth length detuning and l.ittrow grating lechnicjues [5]: coplier mirrors provided broadband tuning and a higher intracavity power capability than the ZnSis mirrors allowed; and the extraction efficiency determinad from the optical output and e heam speciral effects agreed

W'ith this strong foundation and motivated by the polential applications described in Section III, we decided lo test the broadband tunability of the system again in April, 1988 lsing, the lwo coptere mirsors for the cavity, one of which had the $1-\mathrm{mm}$ dinm hole fol coupling the radiation through the Znte window we had the following results:

1) I asing was ohserved from 10 10 $45,4 m$ as evidenced by defecting the fundamental, second harmonic, or thisd hatmonic oficical output and/or the electron beam special ellects 
2) We demonstrated transport of charge through the wiggler at energies as low as $5 \mathrm{MeV}$ (corresponding to $\lambda \sim 150 \mu \mathrm{m}$ ) by reducing the field in both accelerators $A$ and $B$ and by using the second accelerator as a decelerator.

3) We observed a dramatic increase in detected optical power when the fundamental wavelength was about $30 \mu \mathrm{m}$. These features were consistent with lasing on the third harmonic $(10 \mu \mathrm{m}$ where the detectors and windows are optimized). A more thorough investigation of this aspect was performed just after the Conference and the laser operated on the third harmonic down to $3.4 \mu \mathrm{m}$.

Limitations in this preliminary experiment included the liquid helium cooled, $H_{y}$ doped germanium detectur's insensitivity to wavelengths longer than about $18 \mu \mathrm{m}$, the $\mathrm{ZnSc}$ window transmission cutoff at $\sim 22 \mu \mathrm{m}$, and vignetting of the large optical modes by the structures of the resorator cavity (including the wiggler gan itself). Nevertheless, the obtained broadband tuning over a factor of $4 \frac{1}{2}$ is notable as shown in Fig. 2. The solid circles indicate a few of the actual wavelengths generated based on the FFL resonance relation and the e-beam energies measured in the electron spectrometer located after the wiggler. In addition, the figure shows the projected longer wavelength operation one could obtain with e-beam energies down to $5 \mathrm{MeV}$. The curvature of the solid curve is due in the wavelength's $1 / \gamma^{2}$ dependence.

\section{H. Proposed Modifications}

We envision several modifications to the experiment that would dramatically improse our capabilities. The Phase I modifications are mostly the defectors, windows, and wiggles gap. The Phase II major modifications involve changing the injector to a photoinjector, the addition of a third accelerator, and reduction of the geometrical aperturing in the resonator cinvity.

In Phase I, which will have partial financial support from inle:nal institutional runding. we foresece the following:

1. Letsesters At least une Zn-doped (ie detectom that is sensitive lo ahout 45am will be procured to supplement the Hg doped (iermanium delecten Also our pyrelectice devices can be used over the extended wavelength ranpe once the ZnS. window is replaced. 
2. Window's: The resonator window for coupling the radiation out to the external detectors will be changed to diamond or $7 \mathrm{PX}$, both of which should transmit to $100 \mu \mathrm{m}$.

3. Yignetting: The wiggler gap will be enlarged to accommodate the larger modes of the longer wavelength radiation. Minor beamline changes will be made where posrible. A set of simulations is on hand as described below.

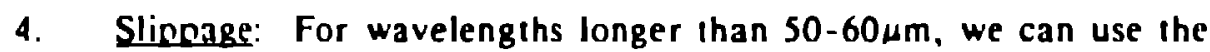
nonisochronous $60^{\circ}$ bend as a magnetic debuncher to lengthen the micropulse temporal width to 20-30 ps. Alternatively, we might reduce the wiggler's length.

Our efforts will be guided by FFI. numerical simulations. Table II shows a summary of long-wavelength calculations for the present facility. Cases involving nominal wavelengths of $10,50,100$ and $150 \mu \mathrm{m}$ were considered. The electron energy, the wiggler half-gap, the peak wiggler field parametel $\left(A_{w^{\prime}}\right)$, the emply cdvity loss, and the small signil gain are shown. The actual wavelength value for maximum small signal gain is in the first colum:n. The calculations were performed with a single pass simulation code, and it was assumed that the cavity was not a limit and that the mirrors were larger than the node size. It was found that the vignelting losses due to the wiggter aperture itself define the losses when all other apertures are removed. () the two possible strategies of shortening the wiggler or opening the gap, the latter was chosen as a first try.

The gai) was adjusede in keep the losses to about ?o'm, and the effects on the wiggles fields as the gan was opened were calculated. In all cases tabulated, the gain was shown to be sufficiently greater than the Iosses so that lasing, would be expected. 'These results uide' added to I ig. 2 as the triangles and complentent the lower-energy beam transpoil demonstration. In practice, the actual mirror sizes and the o()" hend magnet gap may have to be changed since they cause additional lossies. (hanges fo these would have fo be under Phase II.

In Phase II, a photoelect:ic injector, a thitd acceleratur tank, and a new isochountus 6)" bend are the main modifications planned under anofher base propram. The impowed emitlance provided by the injector and acceletation uf to 35 a) Me should allou lasing an

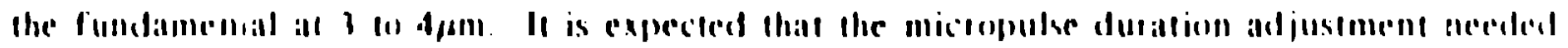
fol very lonk wavelength luning will be hanelled hy altering the length of the lase' 
micropulse that drives the photocathode. Use of larger mirrors (perhaps $30-\mathrm{cm}$ diam) in the resonator cavity would require extensive, but straight forward, mechanical modifications to the beamline.

\section{POTENTIAL APPLICATIONS OF THE MIRACLE FACILITY'}

Although there are a number of potential applications for which FELs have been considered, the wavelength regime from 3 to $160 \mu \mathrm{m}$ has its ow special set. Space limıations preclude a full discussion, so one example each from matarials science and biophysics is cited.

\section{A. High-Temperature Superconductors (HTSCs)}

It has been proposed and discussed separately at this conference [6], that an infrared FEL sould he tuned across the energy gap of a HTSC sample for $T<T_{c}$. Reflection and transmission measurements done as a function of irradiation wavelength and temperature should determine the gap magnitude. The FEL's monochromatic, coherent, and polarization features should simplify the analysis procedures used so that a iwo-angle reflection measuiement could naracletize the coniplex index. The FEL, would be a unique probe in this regard. This source also avoids the complications of broadband irradiation of the sanple. Only the Phase I modifications are needed for this experiment for a $T_{c}-100 k$ sample and assuming an energy gan of $31 / 2 \mathrm{kT}_{\mathrm{c}}$.

\section{H. DNA Snectroscony}

A number of vibrational modes have been observed or calculated for IDNA strucrure Some of these would be accessible depending on the lills range. In partizular, the region from $200101000 \mathrm{em}{ }^{3}(101050 \mu \mathrm{m})$ includes part of the biologically significant region described by Van Zandi, 17]. Spectroscony effects due to temperature, salinity of solutions, binding of drugs, elc. would be studied. The micropulse structure woukd be useful in determining lifetimes of vibrational modes with la'ge bandwidth. These studies would provide tests of the bresent modeling capability for these systems.

\section{SUIMIMAKY ANI) CONCIUISIONS}

In summary. the proposed modifications fo the I os Alamos I: t should allon

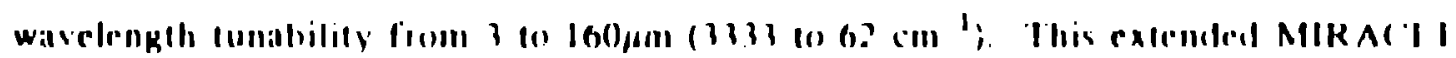


facility would fill the existing wavelength gap among the operating FELs internationally. Specific application to high-temperature superconductors and DNA spectroscopy are envisioned. Successful experiments in either one of these proposed applications would herald a significant, new research technique in that field.

\section{REFERENCES}

I. R. W. Warren, B. E. Newnam, W. E. Stein, J. G. Winston, R. L. Sheffield, M. T. Lynch, J. C. Goldstein, M. C. Whitehead, O. R. Norris, G. Luedemann, T. O. Gibson, and C. M. Humphry, "First Operation of the Los Alamos Free-Electron Laser Oscillator," Proceedings of the International Conference on Lasers 83, pp. 316-320 (1983).

2. Brian E. Newnam, el al., IEEE Journal of Quantum Electronics, Vol. QE-21, No. 7, 867, (1985).

3. R. W. Warren, et al., "Near-Ideal Lasing with a Uniform Wiggler," these Proceedings.

4. D. W. Feldman, et al., "High Extraction Efficiency Experiments with the Los Alamos Free-Electron Laser," these Proceedings.

5. J. E. Sollid, et al., "Sideband Supnression in the Los Alanos Free-Electron Laser using a Littrow Grating, these Proceedings.

6. Alex H. Lumpkin, "Potential Application of the L.os Alaınos Free-Electron Laser: High-Temperature Superconductors," these Prisecdings.

7. I. L. Van Z.andı, V. K. Saxena, and W. K. Schroll, "Hiological Significance and Insignificance of DNA Vibrations," to be published.

\section{I)IS I.AIMFKR}

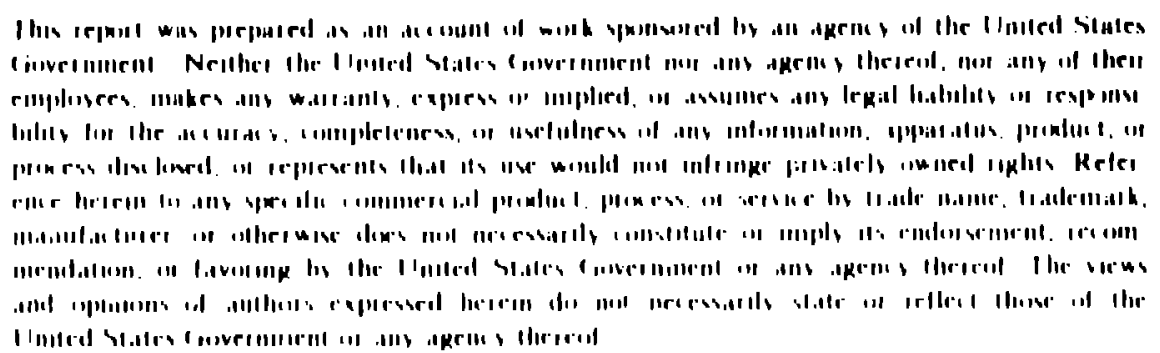


$-7-$

\section{FIGURE CAPTIONS}

Fig. 1. Schematic layout of the present Los Alamos Rf-linac-driven Free-Electron Laser.

Fig.2. Observed and potential broadband tuning aspects of the Los Alamos FEL. Solid circles show lasing wavelengths demonstrated or inferred from harmonic production. The triangles represent the results of FEL simulations assuming the wiggler gap is the critical aperture. 


\section{TABLE I}

\section{NOMINAL FEL PROPERTIES AT 10 MICRONS}

$\begin{array}{ll}\text { Bandwidth: } \Delta \lambda / \lambda & \sim 0.3 \% \\ \text { Micropulse Duration: } & 10-15 \mathrm{ps} \\ \text { Pulse Separation } & 46 \mathrm{~ns} \\ \text { Macropulse } & 10-100 \mu \mathrm{s} \\ \text { Polarization } & \text { Linear }(\sim 100 \%) \\ \text { Focusability } & \text { Diffraction Limited } \\ \text { Power (Peak) } & 10 \mathrm{MW} \\ \text { Power (Ave.) } & 1 \mathrm{~W}\end{array}$

Basic Equation:

$\lambda_{L}=\frac{\lambda_{W}}{2 \gamma^{2}} \quad\left(1+1 / 2\left(A_{W}\right)^{2}\right)$

where

$\lambda_{W}=2.73 \mathrm{~cm} \quad$ wiggler period

$\gamma=42 \quad$ Lorentz factor

$A_{W}=0.76 \quad$ wiggler field parameter 


\section{TABLE II}

\section{Summary of long-wavelength calculations for Los Alamos FEL Facility}

\begin{tabular}{|c|c|c|c|c|c|}
\hline $\begin{array}{l}\text { Optical } \\
\text { Wavelength } \\
\text { ( } \mathrm{em})\end{array}$ & $\begin{array}{c}\text { Electron } \\
\text { Energy }(\gamma)^{*} \\
(\mathrm{Mev})\end{array}$ & $\begin{array}{l}\text { Wiggler } \\
\text { 1/2 Gap } \\
\text { (cm) }\end{array}$ & $\begin{array}{l}\text { Peak Wiggler } \\
\text { Field }\left(\mathbf{a}_{\mathbf{w}}\right) \\
\text { (g) }\end{array}$ & $\begin{array}{c}\text { Empty } \\
\text { Cavity Loss** } \\
(\%)\end{array}$ & $\begin{array}{c}\text { Small } \\
\text { Signal Gain } \\
(\%)\end{array}$ \\
\hline 10.3 & $\begin{array}{c}21.5 \\
(42.0)\end{array}$ & 0.41 & $\begin{array}{l}3000 \\
(.76)\end{array}$ & 3 & 68 \\
\hline 51.4 & $\begin{array}{c}9.4 \\
(17.9)\end{array}$ & 0.55 & $\begin{array}{l}2329 \\
(.59)\end{array}$ & 21 & 260 \\
\hline 102.7 & $\begin{array}{c}63 \\
(12.0)\end{array}$ & 0.78 & $\begin{array}{l}1387 \\
(35)\end{array}$ & 21 & 135 \\
\hline 153.9 & $\begin{array}{c}4.9 \\
(9.7)\end{array}$ & 0.94 & $\begin{array}{l}949 \\
(.24)\end{array}$ & 22 & 95 \\
\hline
\end{tabular}

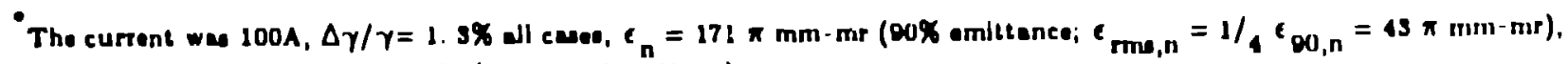
single wavefront celculatione only ( $\mathrm{e} w$, no pulae offects).

- The asumed reflectivity of the mirror in all case wa $07 \%$; the losees represent the effect of operturing by the wiggler

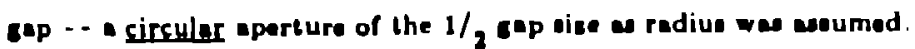




\section{PRESENT LOS ALAMOS FEL}

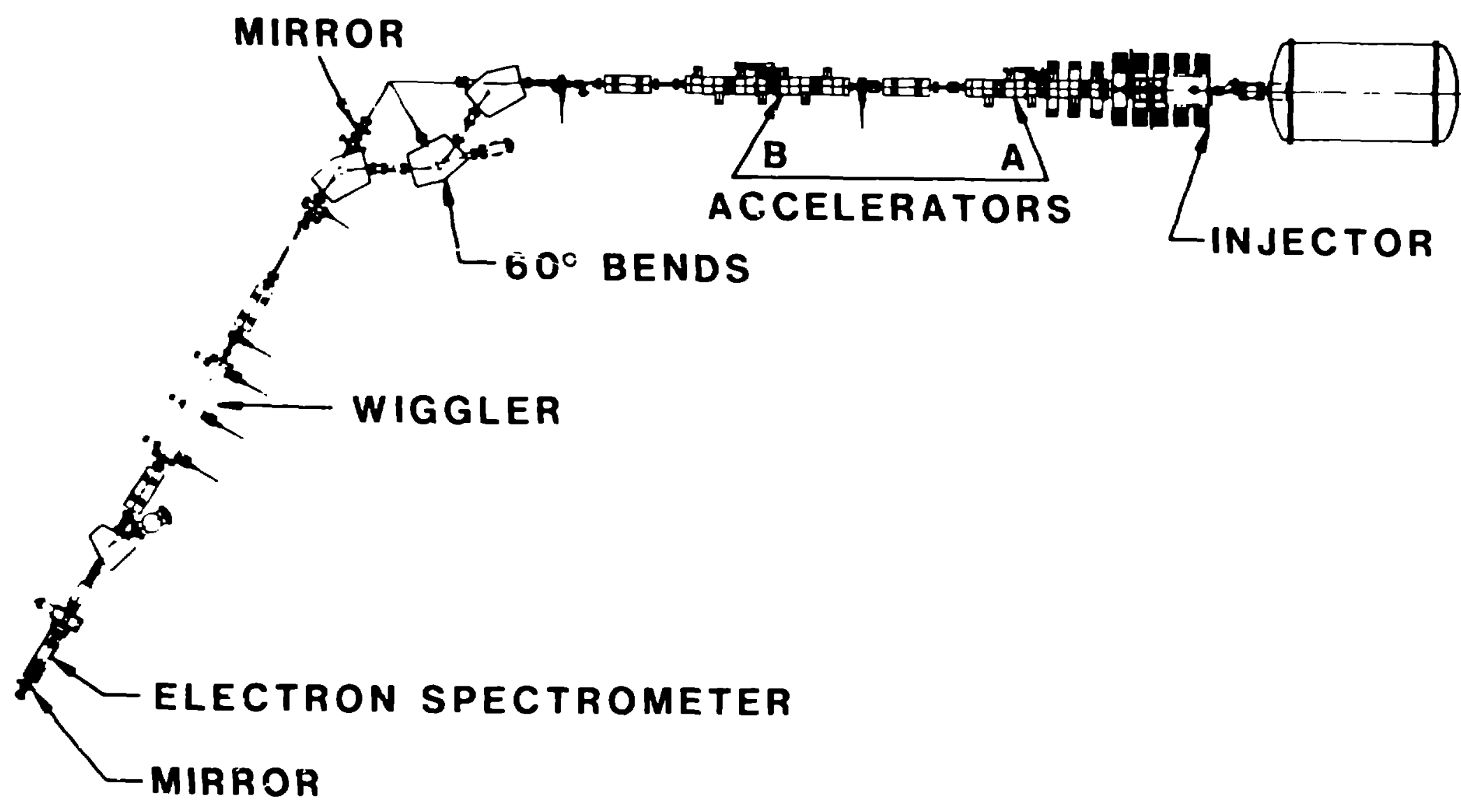




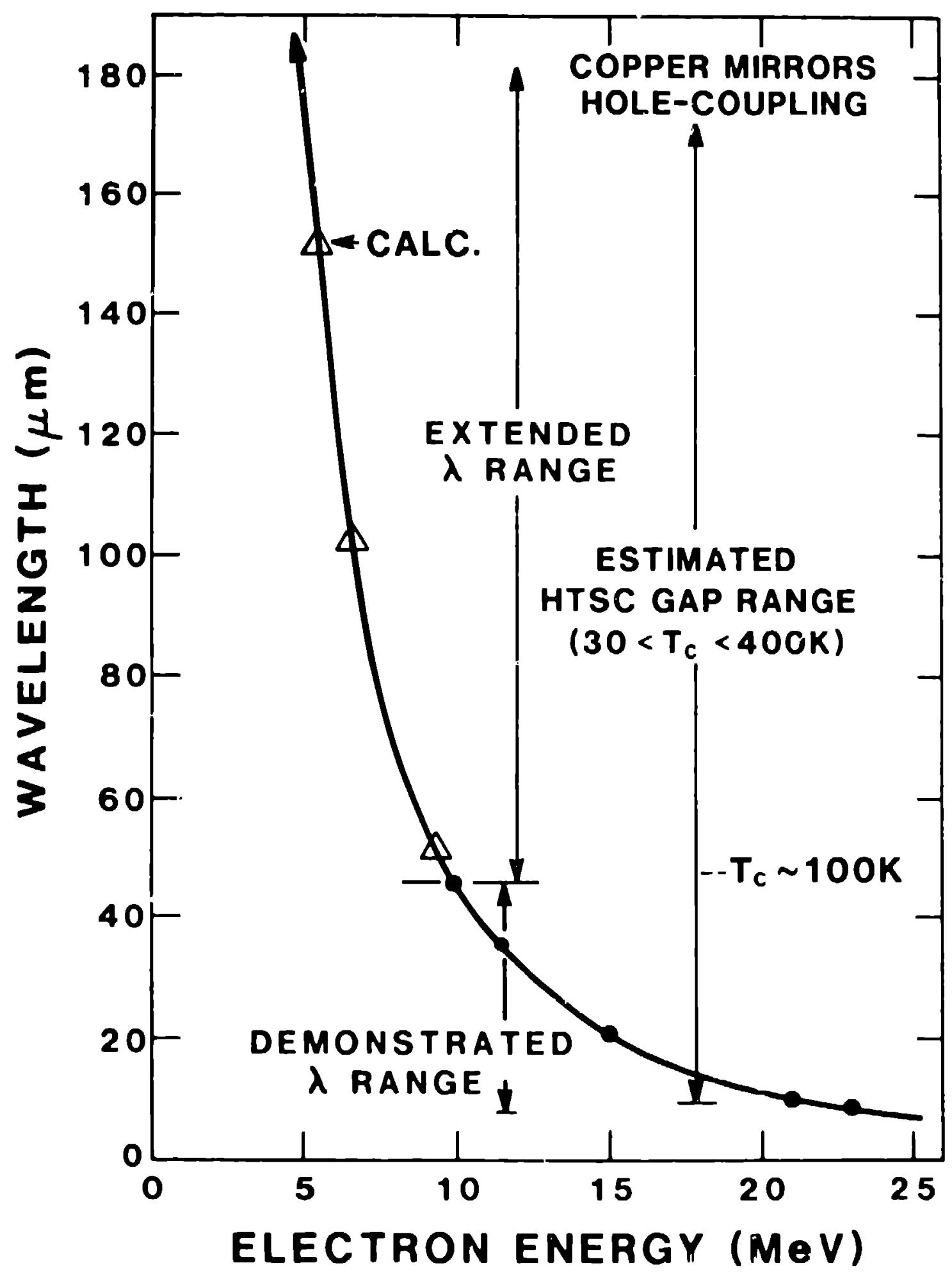

